\title{
Letter from the editor
}

Since the start of the MaRBLe program at the Faculty of Psychology and Neuroscience in 2009, four cohorts of students have been given the opportunity to complete an extensive research project as their Bachelor's thesis. In this special issue you will find contributions from students of each of those cohorts, who conducted their research in the area of Psychology and Law. The first article is an experience report describing the entire process from choosing a topic to finishing the thesis and presenting the results at a student conference. This article is especially of interest to students who are planning to participate in MaRBLe in the coming years. The remaining six articles are short research reports, each describing a different research project.

The format of this special issue was inspired by the format of the open access in-mind journal (http://beta.in-mind.org/). The articles are short and mostly written without the use of jargon. For each article, there is a glossary in the end.

All papers in this special issue were authored and reviewed by students. I was impressed not only by the quality of the submissions, but also by the proficiency with which the student reviewers fulfilled their task giving detailed and skilled feedback to their fellow students. Similarly impressed was I by the fact that students submitted their manuscripts, reviews, and revisions in such a short timeframe. This resulted in a publication processthat authors and editors can normally only dream of.

All this speaks to the importance of MaRBLe and I hope that many more issues will follow. But mostly, I hope that the authors enjoyed working on this issue as much as I did.

Melanie Sauerland 


\section{Letter from the MaRBLe coordinator}

While Wilhelm von Humboldt is credited with the founding principle of the university as a collaboration between learning and research, the underlying goal of education as developing the enquiring mind is very much older:

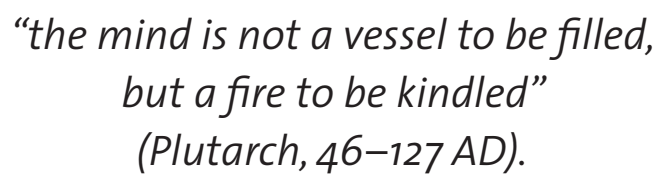

Teaching students to be enquiring or research-based in their approach is not just a throwback to quaint notions of enlightenment but central to the hard-nosed skills required of the future graduate professionals. Since the start in 2009 MaRBLe has exemplified that when learning and research go hand in hand, remarkable progress is made by students and staff alike. MaRBLe has kindled many fires and many of these fires have shed their light on themes in the domain of Psychology and Law. For this reason, I am extremely pleased that one of our eminent researchers and MaRBLe supervisor from day one, Melanie Sauerland, agreed to act as editor for this special issue of the MaRBLe Series. This issue is a wonderful showcase of 4 generations of MaRBLe research on Psychology and Law.

I wish you a very inspiring read!

Dr Arie van der Lugt

MaRBLe coordinator Psychology \& Neuroscience 